\title{
WODAK, R. \& MEYER, M. (ORGS.). METHODS OF CRITICAL DISCOURSE ANALYSIS. LONDRES, THOUSAND OAKS, NOVA DELHI: SAGE PUBLICATIONS, 2001, 200 PÁGS.
}

\section{Resenhado por: Maria Aparecida Ottoni}

Essa obra fornece uma introdução à Análise de Discurso Crítica (ADC) muito necessária, pertinente e consistente tanto para pesquisadores/as iniciantes quanto para os/as mais experientes. O texto dá uma visão geral das várias teorias e métodos associados a essa abordagem, e apresenta aos/às leitores/as os/as principais protagonistas no campo e os métodos com os quais eles/elas estão mais intimamente relacionados/as. Isso é feito por meio de sete capítulos que compõem o livro, sendo dois de Ruth Wodak - o primeiro e o quarto -, e os outros cinco de: Michael Meyer (Cap. 2), Siegfried Jäger (Cap. 3), Teun A. van Dijk (Cap. 5), Norman Fairclough (Cap. 6) e Ron Scollon (Cap. 7).

O Capítulo 1, de Wodak, intitulado Sobre o que é a $A D C$ - um resumo de sua história, conceitos importantes e seus desenvolvimentos, é de fundamental importância nessa obra. Nele, a autora relata como a ADC emergiu, no início dos anos 90, como uma rede de estudiosos: um 'nobre grupo científico'; narra a história da Lingüística Crítica (LC) e Análise de Discurso Crítica (ADC); fornece aos(às) leitores(as) uma descrição geral de alguns princípios teóricos básicos das duas abordagens e breves descrições das escolas mais proeminentes que emergiram em LC e ADC, fazendo, assim, o que podemos chamar de uma 'revisão da literatura'. Essa é, sem dúvida, de suma relevância. Além disso, a autora finaliza o capítulo com a seção Perguntas abertas e perspectivas, na qual ela apresenta algumas questões que, durante os anos, surgiram como agenda de pesquisa e que não têm ainda sido discutidas adequadamente. Elas são centrais para as contribuições desse livro e são discutidas no capítulo seguinte, de Michael Meyer, Entre teoria, método, e política: posição das abordagens de ADC. 
Esse segundo capítulo, a nosso ver, poderia ter sido o sétimo e último dessa obra, uma vez que o seu objetivo é fornecer um pequeno resumo das abordagens de ADC, as suas semelhanças e diferenças. E, ao fazer isso, Meyer faz referência a todos os outros capítulos do livro e comparações entre eles, as teorias e os métodos adotados. Julgamos que essa mudança na estrutura do livro contribuiria para uma melhor fruição na leitura da obra e melhor entendimento das comparações tecidas pelo autor.

No primeiro tópico, $A A D C$ como uma diferença que faz diferença, Meyer argumenta que a ADC difere de outras abordagens sociolingüísticas, por vários motivos, os quais são por ele elencados, e aponta algumas características importantes da ADC, a qual, para ele, é fortemente baseada em teoria. Nessa obra, por exemplo, como sintetiza Meyer, encontramos uma ampla variedade de teorias, desde perspectivas microssociológicas (Ron Scollon) a teorias sobre sociedade e poder na tradição de Michel Foucault (Siegfried Jäger, Fairclough, Ruth Wodak), teorias sobre cognição social (Teun van Dijk) e gramática. Essa diversidade de posições dentro da ADC e a adoção de componentes teóricos de origens muito diferentes são exemplos de que não há um ponto de vista teórico considerado como guia e que seja constantemente usado em ADC. Da mesma forma, quanto à Metodologia de coleta de dados, Meyer afirma que não há uma forma típica de coletar dados em ADC. O autor salienta que, embora não haja nenhuma metodologia exclusiva de $\mathrm{ADC}$ e que dê conta de tudo, há algumas características comuns à maioria das suas abordagens, as quais ele sintetiza.

O título do último tópico desse capítulo, Conclusão: ADC em cima do muro, parece-nos bem sugestivo da posição de Meyer em relação à ADC. Há, a nosso ver, uma crítica implícita nesse título. A possível relação estabelecida entre a diversidade - característica da ADC - e a expressão 'em cima do muro' pode levar os/as leitores/as a perceber um 'tom pejorativo', uma visão 'não-positiva' dessa diversidade. Meyer termina o capítulo dizendo que "Portanto, críticos como Widdowson (1995) objetam que a $\mathrm{ADC}$ constantemente fica em cima do muro entre pesquisa social e argumentação política" (p. 30-31), o que parece retomar e reforçar a crítica implícita no título acima. No entanto, o pesquisador não explicita, claramente, a sua validação dessa crítica. 
Com relação ao Capítulo 3, intitulado Discurso e conhecimento: aspectos teóricos e metodológicos de um discurso crítico e análise de dispositivo, inicialmente Siegfried Jäger apresenta algumas questões centrais a uma ADC baseada na teoria de discurso de Michel Foucault. Jäger, segundo Meyer (nessa obra, p. 20), descobre uma 'mancha opaca' na teoria de Foucault: a mediação entre sujeito e objeto, entre práticas discursivas e não-discursivas (atividades), por um lado, e manifestações (objetos), por outro. E, assim, Jäger tenta reposicionar a definição de Foucault de discurso a qual é muito fortemente alcançada no verbal. Por essa razão, reinventa o conceito foucaultiano de dispositivo como uma 'concha' que envolve práticas discursivas e não-discursivas e materializações. Ele desenvolve, ainda, um programa de pesquisa e metodologia que permite a análise em vários passos, visando explicitamente à análise de discursos e dispositivos (análise de discurso estendida para incluir análise de dispositivo). Entendemos que as suas diretrizes analíticas para processamento dos dados são bem abrangentes e podem auxiliar muito na condução de análises de discurso críticas, mas não podem ser vistas como uma receita - como ele mesmo ressalta.

No Capítulo 4 - A abordagem discursiva-histórica, de Ruth Wodak, ela introduz um novo enfoque à necessidade de uma perspectiva histórica - $a$ abordagem discursiva-histórica. Ela mostra como diferentes estudiosos/as que se engajaram em lingüística, semiótica e análise de discurso compartilham uma perspectiva particular na qual figuram três conceitos: o conceito de poder, o conceito de história e o conceito de ideologia. De acordo com a autora, a primeira questão a ser encaminhada pelos/as pesquisadores/as é: 'Quais ferramentas conceituais são relevantes para este ou aquele problema e para este ou aquele contexto?' (p. 64).

A autora explica que os passos, nessa perspectiva, são dados várias vezes, sempre indo e vindo entre o texto, a etnografia, as teorias e a análise; e as decisões, que são requeridas e tomadas, têm que ser explicitadas e justificadas. Wodak advoga que a pesquisa em ADC deve ser multiteórica e multimetodológica, crítica e auto-reflexiva; e sugere procedimentos de triangulação - como também o faz Scollon no último capítulo - para assegurar a validade da pesquisa e como um modo para analistas críticos minimizarem o risco de ser parciais/tendenciosos. Ela se centra no estudo de discursos 
de discriminação e, para exemplificar, apresenta a análise de um discurso discriminatório: o estudo de caso da petição FPO 'Austria First' 1992-3. Sua análise é bastante consistente e a sua apresentação é bem didática, o que facilita muito o acompanhamento e entendimento por parte dos/as leitores/as. Contudo, as figuras apresentadas, como a da p. 69, são bastante complexas, o que, ao contrário do que acontece na sua análise, dificulta muito o entendimento por parte dos/as leitores/as. Dever-se-ia, talvez, tentar esboçar esquemas mais simplificados e claros para um melhor acompanhamento por parte de um amplo público.

Com relação ao Capítulo 5, A ADC e a multidisciplinaridade: em busca da diversidade, nele, van Dijk faz questão de frisar que não está oferecendo um 'método van Dijk' já pronto para se fazer $\mathrm{ADC}$, ao formular princípios e diretrizes práticas para se fazer esse tipo de análise. $\mathrm{O}$ autor destaca, ainda que não tem tal método, não conduz ou representa uma 'abordagem', 'escola' ou outra seita, nem pretende ter seguidores, pois entende que isso é uma forma de subserviência acadêmica incompatível com uma atitude crítica. Para esse pesquisador, a ADC é uma perspectiva - crítica - de fazer pesquisa: é análise de discurso 'com uma atitude'. Ao contrário de muitos outros estudos, ele destaca que a ADC não nega, mas, explicitamente, define e defende sua própria posição sociopolítica. Isto é, a ADC é parcial e orgulhosa disso.

Podemos dizer que van Dijk está mais no lado sócio-psicológico do campo de ADC. A tríade focal dele é interpretada entre discurso, cognição e sociedade, e representada por um triângulo. Para ele, a ADC deveria estar baseada em uma sólida teoria de contexto e, nesse sentido, argumenta que a teoria de jogos de representações sociais desempenha uma parte principal. De acordo com van Dijk, os discursos só podem ser entendidos na interação entre situação social, ação, ator e estruturas da sociedade. Assim, diferente de Jäger, ele conceitua a influência da estrutura social via representações sociais.

Já em A Análise de discurso crítica como um método na pesquisa científica social, Capítulo 6, Fairclough objetiva descrever a ADC como um método que pode ser usado em pesquisa científica social, fazendo referência especificamente a um objeto de pesquisa particular: como a linguagem figura distintamente no novo capitalismo. Contudo, já no início de seu texto, ele 
declara ter certas reservas sobre o conceito de 'método', pois esse pode muito facilmente ser tomado como um tipo de 'habilidade transferível', se se entender um 'método' como sendo uma técnica, uma ferramenta em uma caixa de ferramentas, à qual se pode recorrer quando preciso e, então, devolver à caixa. Para evitar esse possível mal entendido, Fairclough defende, como o fez juntamente com Chouliaraki, em 1999, que a ADC é tanto teoria quanto método, no sentido de que é uma perspectiva teórica sobre a linguagem e, em geral, a semiose como um elemento ou 'momento' do processo social material, que dá origem a modos de analisar a linguagem ou semiose dentro de análises mais amplas do processo social. Além disso, explica que a ADC é uma teoria e um método que estão em uma relação dialógica com outras teorias sociais e métodos, com os quais deveria se engajar de um modo 'transdisciplinar' mais que apenas de um modo interdisciplinar.

Sem dúvida, esse texto vem contribuir muito para o enriquecimento do que havia sido apresentado por Chouliaraki \& Fairclough (1999). A análise empreendida por Fairclough torna mais clara a aplicabilidade do arcabouço proposto em 1999, cuja apresentação e redação foram um pouco modificadas por ele neste trabalho. Entendemos que tais modificações tornaram-no mais claro. Em uma primeira leitura, podemos achar que o autor excluiu a análise da conjuntura presente no item 2(a), do modelo de 1999, o que nos causa certa estranheza, mas, ao atentarmos para a explicação dada por Chouliaraki e Fairclough (1999: 61) para esse item da análise, vemos que se encaixa perfeitamente no que Fairclough põe no item 2(a), neste capítulo. Para melhor visualização dessas alterações e análise pelos/as leitores/as, sugerimos que os dois arcabouços sejam comparados.

Fairclough faz uma interessante e consistente análise de dois textos, na qual ele enfoca o conflito social na tradição marxista e tenta descobrir suas manifestações lingüísticas nos discursos, em particular elementos de dominação, diferença e resistência. Ele segue passo a passo o arcabouço, dando uma idéia bem abrangente de como aplicá-lo, e explora, mais que em trabalhos anteriores, a análise textual, baseada na Linguística Sistêmico-Funcional (Halliday, 1985). Isso é um ponto bem positivo no seu trabalho, pois pode-se dizer que ainda há certa dificuldade por parte dos/as analistas de detalhar essa parte do arcabouço. 
Já no sétimo e último capítulo, Ação e texto: para um entendimento integrado do lugar do texto na (inter)ação, da análise de discurso mediada e do problema da ação social, Scollon centra-se nas ações sociais. Ele argumenta que ainda é problemático para o programa de ADC estabelecer os elos entre discursos e ações sociais. Por isso, propõe uma abordagem chamada Análise de Discurso Mediada (ADM), a qual, segundo ele, partilha os objetivos da ADC, mas focaliza as ações sociais. Seu objetivo mais geral é explicar a ligação entre questões sociais amplas e a conversa e escrita cotidianas, e chegar a uma compreensão mais rica da história da prática dentro do habitus dos participantes em uma ação social particular. O autor enfatiza que todas as ações sociais são mediadas através de ferramentas culturais ou meios mediacionais, dos quais o mais saliente e talvez o mais comum seja a linguagem, ou, para usar o termo que Scollon prefere, discurso. Ele relaciona teoricamente o nível micro de ação com o nível macro de comunidades por meio de seis conceitos, os quais se constituem em níveis analíticos.

Scollon tenta estabelecer algumas diferenças entre a ADM e a ADC. Contudo, o que ele apresenta, a princípio, como distintivo das duas abordagens não é suficientemente convincente. Exemplificando, o autor afirma que a ADM considera que as relações de poder na sociedade não são só discursivas, mas são baseadas, ao contrário, na prática. Isso, podemos dizer, também se aplica à $\mathrm{ADC}$, uma vez que essa não considera que tais relações sejam somente discursivas. Dessa forma, indagamos: onde estaria a distinção? Talvez, mais adiante, ele tenha sido mais feliz ao tentar estabelecê-la, quando resume a diferença entre as duas abordagens como uma diferença de foco: a linguagem (ou discurso) não é o foco central da ADM, mas, sim, a ação social, independentemente de a linguagem (ou discurso) estar envolvida ou não. $\mathrm{E}$, tendo em vista que o foco da ADM não é o discurso, no final do capítulo, o autor apresenta uma interessante questão que pode daí originar: A ADM deveria ou não ser chamada de análise de discurso? De acordo com Scollon, a resposta é 'sim', e ele apresenta duas razões convincentes para isso, o que nos fez concordar com ele.

Malgrado ser muito extenso, esse capítulo desempenha papel importante no livro por trazer uma abordagem diferenciada e uma análise 
bem aprofundada e fundamentada teoricamente, apesar de não fornecer quaisquer operacionalizações ou aspectos lingüísticos que deveriam ser analisados em seu esquema analítico.

Para finalizar, consideramos que essa obra é leitura indispensável tanto para estudantes como para pesquisadores/as nos campos da Lingüística, Sociologia, Análise de Discurso e Psicologia Social. Ela inclui uma consistente e relevante seção introdutória, apresentando o histórico, conceitos e orientação metodológica da $\mathrm{ADC}$; tem uma ampla cobertura, pois traz juntas as cinco principais abordagens à $\mathrm{ADC}$, representadas pelas contribuições dos cinco autores, e ainda apresenta um balanço fundamental entre teoria e aplicação, com uma ênfase comparativa e ampla exemplificação. Isso pode dar aos/às leitores/as a oportunidade de entender melhor, praticar, comparar os métodos e escolher o(s) mais apropriado(s) à(s) questão(ões) de sua pesquisa.

Ademais, as leituras adicionais sugeridas ao final de cada capítulo da obra, não só por meio de indicação bibliográfica como também por meio de breves resenhas, constituem um fator positivo adicional na forma de organização do livro e são de grande auxílio para os/as que se interessam em se aprofundar nas questões tratadas.

\section{REFERÊNCIAS BIBLIOGRÁFICAS}

Chouliaraki, L. \& Fairclough, N. Discourse in late modernity. Rethinking critical discourse analysis. Edimburgo: Edinburgh University Press, 1999. Halliday, M. A. K. Introduction to functional grammar. Londres: Arnold, 1985. Widdowson, H. G. Discourse analysis. A critical view. Language and Literature, 4 (3): 157-72, 1995. 